\title{
HISTORIA DESCONOCIDA. UNA APORTACIÓN A LA HISTORIA DE LA IGLESIA EN LA INDEPENDENCIA DE MÉXICO ${ }^{1}$
}

Ana Teresa López de Llergo

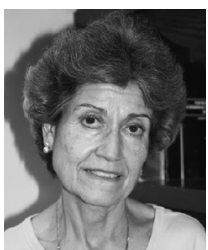

Doctorado en Ciencias de la Educación, Universidad de Navarra, España.

Maestría en Pedagogía, Universidad Panamericana, México.

Licenciatura en Ingeniería Química y Química Industrial, Universidad Iberoamericana, México.

Autora de: Hacia un desarrollo humano, Ed. Limusa; Valores, valoraciones y virtudes, Ed. CECSA.

Correo electrónico: [alopezde@up.edu.mx].

La historia muestra un gran mosaico de acontecimientos que, en conjunto, ofrecen una panorámica de claroscuros. Como son tan vastos los sucesos, muchas veces faltan piezas. Por eso, la Sociedad Mexicana de Historia Eclesiástica da a conocer, con sus investigaciones, hechos importantísimos y poco difundidos.

Este libro es el tercero que publica la Sociedad. Resulta una auténtica joya, por el modo de abordar los asuntos y por la oportunidad del tema, precisamente para el año de la conmemoración del Bicentenario de nuestra Independencia. Anteceden los libros anuales de 2007 y 2008.

1 Memorias de la Sociedad Mexicana de Historia Eclesiástica, A.C., Minos III Milenio, México, 2009. 
La presentación del libro está a cargo de Mons. Alberto Suárez Inda, Arzobispo de Morelia y Presidente de la Comisión Episcopal para la Conmemoración del Bicentenario de la Independencia y el Centenario de la Revolución Mexicana. Hace mención de la amplia cobertura de los contenidos: como el «Sermón Guadalupano» de Fray Servando a la Orden Imperial de Guadalupe, y las dos primeras «Jornadas Académicas», promovidas por la Conferencia Episcopal en la Universidad Pontificia de México y en la ciudad de Morelia.

El Tesorero de la Sociedad Mexicana de Historia Eclesiástica, Pbro. Lic. Jaime Barajas García, al presentar el contenido, cita diez estudios monográficos -ocho en los primeros movimientos emancipadores, años de 1794 a 1821, y dos más, en la realización de la Independencia, año 1821—; una introducción, casi desconocida: el «Sermón de acción de gracias a María Santísima», pronunciado el 12 de octubre de 1821; cuatro notas y tres noticias.

\section{LA IGLESIA EN LOS INICIOS DEL MOVIMIENTO EMANCIPADOR}

José Antonio Portillo Valadez realiza un juicio sumario de Fray Servando Teresa de Mier, pues sostiene que sus ideas, escritos y su participación activa promueven la emancipación. Su sermón en el Santuario de Nuestra Señora de Guadalupe, el 12 de diciembre de 1794, es un detonador pues, al plantear el hecho de que Tomás Apóstol estuvo en las tierras americanas, minimiza la labor catequética de los peninsulares.

Un replanteamiento al tan trillado tema de la relegada posición de la mujer en la antigüedad, es una consecuencia del trabajo de José Gerardo Herrera Alcalá y Manuel Ramos Medina sobre las monjas y la Independencia. En el espacio conventual conviven aristócratas con mestizas, indígenas y esclavas. Desde allí, ellas también influyen, gracias a la esmerada formación recibida, y porque también llegaban ahí las ideas políticas y los acontecimientos de la ciudad. Hacia finales del siglo XVIII, Matiana, sirvienta en el monasterio de San Jerónimo de la ciudad capital, predijo revueltas que culminarían con la consumación 
de la Independencia, aunque la explícita voluntad de esta mujer fue fomentar la vida de piedad y la oración. La monja dominica Juana María de la Purísima Concepción, antes que Josefa Ortiz de Domínguez y Leona Vicario, capta y apoya los anhelos de autodeterminación novohispana que descubre en su hermano José Mariano de Michelena. Por otro lado, Miguel Hidalgo cuenta con las oraciones y el beneplácito de las monjas carmelitas de Querétaro, a quienes atiende durante los días que pasa por ese lugar.

Berenice Bravo Rubio y Marco Antonio Pérez Iturbide se dan a la tarea de exponer la fidelidad a Dios y al rey de los tres últimos prelados españoles del Arzobispado de México a través de sus discursos.

«Fray Melchor de Talamantes y el primer proyecto de organización constitucional para el México independiente» es la investigación de Juan Pablo Pampillo Baliño. Talamantes nace en Lima y allí tiene noticias de las ideas precursoras de la independencia de ese país. Llega a la Nueva España en 1799, se hospeda en el convento de la Merced de la capital y pronto alcanza reconocimiento social e intelectual. Tiene acceso a gran cantidad de documentos, por eso, su pensamiento se caracteriza por la ilustración, el iusnaturalismo moderno racionalista y el cristianismo de la segunda escolástica, particularmente de Francisco Suárez. En su escrito El Congreso Nacional del Reino de la Nueva España, defiende la soberanía política de las colonias y en la propuesta de integración del Congreso manifiesta sus amplias miras, donde se bosqueja el primer proyecto de organización constitucional.

Javier Martín Ruiz, cronista de la ciudad de Irapuato, señala los once años de guerra insurgente en ese lugar, caracterizada por un intenso contenido religioso, por la búsqueda de la justicia, por una orientación indigenista y campesina, por último: por su alejamiento con la capital del virreinato. Irapuato fue testigo del comienzo del movimiento de Independencia y aportó y sufrió para la feliz realización de tal causa.

El siguiente tema que aborda Isaac Luis Velásquez Morales es la estancia de Miguel Hidalgo en Santiago Tianquistenco. Para evitar 
puntos estratégicos adversos al ejército insurgente, Hidalgo decide ir a Santiago; en su recorrido es probablemente, en ese lugar, donde Allende planea la estrategia para la batalla del Monte de las Cruces.

Jesús Joel Peña Espinoza, realiza un estudio desde la correspondencia, para investigar la postura del clero diocesano de TlaxcalaPuebla ante la insurgencia. El 26 de octubre de 1810, el Obispo Manuel Ignacio González del Campillo cita al clero; al día siguiente 289 clérigos del coro de la Catedral manifiestan su apoyo al gobierno virreinal y están dispuestos a combatir la insurrección. A partir de entonces se establece una riquísima correspondencia de la diócesis que se encuentra actualmente en el Archivo del Cabildo Metropolitano de Puebla. Más adelante, el Obispo poblano es la figura de mayor importancia que se enfrenta a José María Morelos. Al fallecer González del Campillo, en 1913, le sucede Antonio Joaquín Pérez Martínez, gran impulsor de la independencia, que, por eso, apoya el movimiento trigarante.

Manuel Olimón Nolasco presenta el estilo de vida del Presbítero José María Cos quien, desde la intelectualidad, en el terreno de la teología moral, realiza su actividad pastoral. Entre sus múltiples escritos destaca su «Manifiesto y Plan de Guerra», que defiende y define dentro de una doctrina impecable. El Padre Cos valora el acompañamiento pastoral en medio de los problemas políticos de su tiempo.

\section{LA IGLESIA EN LA CONSUMACIÓN DE LA INDEPENDENCIA}

Esta sección consta de dos artículos, uno se refiere a Agustín de Iturbide, el otro a la Imperial Orden de Guadalupe.

Austreberto Martínez Villegas analiza el papel de Agustín de Iturbide y Arámburu en la Independencia. Miguel Hidalgo le invita a participar en el movimiento, pero Agustín no acepta pues considera aquello como una rebelión anárquica. Más tarde, Iturbide simpatiza con la causa insurgente y lo comunica al Virrey de Apodaca, lo mismo que al Obispo de Guadalajara: José Ruiz de Cabañas. Agustín busca la 
manera de que el Estado defienda la fe y la Iglesia. En el Plan de Iguala se concibe la Independencia bajo la forma de monarquía constitucional, con obediencia a Fernando VII o al monarca Borbón correspondiente. Como ningún miembro de la casa real acepta el trono mexicano, el sargento Pío Marcha exige la proclamación de Iturbide como emperador. Le corona el 21 de julio de 1822. En diciembre de ese año aparecen movimientos reaccionarios en Veracruz. El final de la historia la conocemos. Iturbide se ve obligado a salir del país. Cuando regresa, desconoce que existe una sentencia de muerte que le corresponde. Muere fusilado el 19 de julio de 1824 .

María Cristina Torales Pacheco aborda el tema de la Imperial Orden de Guadalupe. Esta condecoración equivale a las iniciativas de la monarquía española para corresponder a los vasallos fieles, en este caso es un premio para quienes son seguidores del Plan de Iguala. La instituye Iturbide, inspirándose en la Real Orden de Isabel la Católica, establecida cinco años antes por Fernando VII, así como en las de la Real Orden de Carlos Tercero, la Real Orden de San Hermenegildo y la de San Fernando. En los estatutos de la Imperial Orden de Guadalupe se establece un mínimo de 25 años, ser ciudadanos del imperio con méritos patrióticos distinguidos y ser cristianos católicos, apostólicos, romanos. La última condición es indispensable. La máxima autoridad es el Gran Maestre - Iturbide- en representación del pueblo y tres categorías: Grandes Cruces, Caballeros de Número y Caballeros Supernumerarios. Hay una clara estructura jerárquica y tratamientos, trajes, insignias, obligaciones y protocolo para las celebraciones.

\section{DOCUMENTOS}

En esta sección, José Gerardo Herrera Alcalá reproduce el «Sermón de acción de gracias a María Santísima de Guadalupe» por el venturoso suceso de la Independencia. El hecho tuvo lugar en el Santuario insigne, el 12 de octubre de 1821, por el Sr. Dr. y Mtro. D. José Julio García de Torres. Es una acción de gracias por el fin de las hostilidades y la súplica de reconciliación entre criollos. En la Colegiata de Guadalupe, el Illmo. Sr. Dr. Domingo Hernández, con su Senado de 
Canónigos, ofrece a Don Agustín de Iturbide, Libertador de la Nación y autor de la Independencia, el presente Sermón.

\section{NOTAS Y REFLEXIONES BIBLIOGRÁFICAS}

Stella María González Cicero presenta un texto donde se vislumbran los nuevos horizontes de la historiografía, los archivos, los periódicos, los libros, los estudios históricos y las digitalizaciones.

\section{NOTAS Y REFLEXIONES ICONOGRÁFICAS}

Josefa Calderón Paredes realiza un estudio de las pinturas de Alfredo Zalce, en el Museo Casa Natal de Morelos. Analiza la temática histórica y la técnica de manufacturación de dichas pinturas.

\section{NOTAS Y REFLEXIONES TEMÁTICAS}

Francisco Miranda Godínez realiza una investigación sobre los clérigos anticlericales: sacerdotes en la Independencia. Se aborda la influencia del fenómeno del cambio de época, para atisbar nuevos tiempos y asumir nuevas actitudes. Aparece el hecho de las excomuniones, no debidas a la unión a la causa de independencia, sino por haber realizado acciones contrarias a la condición sacerdotal. Y, una vez condenados a muerte, no por el Papa, sino por el Rey de España, cómo buscan y encuentran la reconciliación al morir dentro del seno de la Iglesia.

Rubén Rodríguez Balderas presenta un texto titulado: «Independencia de México e Iglesia católica. Reflexiones históricas sobre la fe de una nación». Con la fuerza de la experiencia, el autor asegura la importancia de la fe católica en el pueblo mexicano, y además, compartida con otros diversos testimonios. Es muy interesante el subtítulo de una de las partes de su texto: «Un secreto a gritos: todos fueron católicos», y allí, entramos cada uno de los lectores, porque para nosotros también es un secreto a gritos: por elemental que sea nuestro conocimiento de la historia patria. El autor afirma que no ha encontrado a ningún personaje no católico que haya contribuido a nuestra emancipación. También afirma 
las atrocidades cometidas por los católicos de ambos bandos, mismas que no se deben a la afiliación a la Iglesia católica, sino a la condición humana. La conmemoración del Bicentenario es una ocasión formidable para revivir nuestras raíces históricas y consolidar la Independencia.

\section{NOTICIARIO}

Juan Carlos Casas García reseña las Jornadas de Historia en la Universidad Pontificia de México, del 12 al 14 de mayo de 2009, con el título «Iglesia, Independencia y Revolución».

Rubén Rodríguez Balderas realiza otra reseña de la II Jornada Académica: «Independencia e Iglesia», organizada por la Comisión del Episcopado Mexicano, el 24 y 25 de septiembre de 2009, para la conmemoración del Bicentenario de la Independencia y el Centenario de la Revolución.

Para cerrar esta edición, se presentan a los nuevos miembros de la Sociedad Mexicana de Historia Eclesiástica, y también se expone un breve currículo de los autores de las distintas temáticas.

\section{A MODO DE CIERRE}

Nunca mejor elegido un título: Historia desconocida. Gracias a la concienzuda investigación de quienes colaboran en esta obra, tenemos a nuestro alcance muchos aspectos que aclaran tantas sombras en nuestro conocimiento. 